\title{
Shoulder diagnoses in secondary care, a one year cohort
}

Niels G Juel ${ }^{1 *}$ and Bård Natvig ${ }^{2}$

\begin{abstract}
Background: Shoulder pain is common in the general population. Reports on specific diagnoses in general populations are scarce and only from primary care. The diagnostic distribution of shoulder disorders in secondary care is not reported. Most of the clinical research in the shoulder field is done in hospital settings. The aim of this study was to identify the diagnoses in a 1-year cohort in a hospital-based outpatient clinic using standardized diagnostic criteria and to compare the results with previous studies.

Methods: A diagnostic routine was conducted among patients referred to our physical medicine outpatient clinic at Oslo University Hospital. Diagnostic criteria were derived from the literature and supplemented with research criteria.

Results: Of 766 patients diagnosed, 55\% were women and the mean age was 49 years (range 19-93, SD \pm 14 ). The most common diagnoses were subacromial pain (36\%), myalgia (17\%) and adhesive capsulitis (11\%). Subacromial pain and adhesive capsulitis were most frequent in persons aged 40-60 years. Shoulder myalgia was most frequent in age groups under 40. Labral tears and instability problems (8\%) were most frequent in young patients and not present after age 50 . Full-thickness rotator cuff tears (8\%) and glenohumeral osteoarthritis (4\%) were more prevalent after the age of 60 . Few differences were observed between sexes. We identified three studies reporting shoulder diagnoses in primary care.

Conclusion: Subacromial pain syndrome, myalgia and adhesive capsulitis were the most prevalent diagnoses in our study. However, large differences in prevalence between different studies were found, most likely arising from different use of diagnostic criteria and a difference in populations between primary and secondary care. Of the diagnoses in our cohort, $20 \%$ were not reported by the studies from primary care (glenohumeral osteoarthritis, full thickness rotator cuff tears, labral tears and instabilities).
\end{abstract}

Keywords: Shoulder, Diagnosis, Prevalence, Hospital outpatient clinics, Age factors

\section{Background}

Shoulder pain is common in the general population with a reported 1-month prevalence of $18-31 \%$ and a 1 -year prevalence of $5-47 \%$ [1-3]. These reports were questionnairebased from unselected community populations. The focus was on pain in the shoulder region reported with varying case definitions. Reports on specific diagnoses in general populations are scarce. We found three studies in this field using an unsystematic literature search in PubMed and browsing bibliographies of relevant articles. Walker-Bone et al. [4] invited all persons with shoulder pain in a survey

\footnotetext{
* Correspondence: uxngju@ous-hf.no

${ }^{1}$ Department of Physical Medicine and Rehabilitation, Oslo University

Hospital, Ullevål, Postboks 4956 Nydalen, 0424 Oslo, Norway Full list of author information is available at the end of the article
}

to a clinical appointment, where the subjects were given diagnoses using a standardised clinical examination. The two largest diagnostic groups by far were adhesive capsulitis and rotator cuff tendonitis at 55\% and 30\% respectively, giving a 1-year prevalence of $9 \%$ and $5 \%$ of these diagnoses in the general population. Two prospective diagnostic studies from general practice $[5,6]$ were also using standardised tests to obtain diagnoses. Östör et al. found rotator cuff related disease to be the most common diagnosis, and it represented up to $86 \%$ of all cases whereas adhesive capsulitis represented 15\%. Van der Windt et al. [6] found that 44\% of the diagnoses were rotator cuff related and found adhesive capsulitis in $21 \%$ of the population. These numbers show large differences in the reported proportions of the various

C Biomed Central

(c) 2014 Juel and Natvig; licensee BioMed Central Ltd. This is an Open Access article distributed under the terms of the Creative Commons Attribution License (http://creativecommons.org/licenses/by/2.0), which permits unrestricted use, distribution, and reproduction in any medium, provided the original work is properly credited. The Creative Commons Public Domain Dedication waiver (http://creativecommons.org/publicdomain/zero/1.0/) applies to the data made available in this article, unless otherwise stated. 
diagnoses in different studies. These differences might be caused by the different populations examined but also by the various sets of diagnostic criteria used. Most of the shoulder diagnoses are based on clinical criteria. Diagnoses such as osteoarthritis, rotator cuff and labral tears also rely mainly on reported pain and positive clinical tests to be confirmed as possible reasons for the patient's pain, although they are in some cases image supported [7]. This is particularly the case in persons aged over 60 years because of the natural and mostly pain-free changes in the tissue that come with age [8-10].

To our knowledge, the diagnostic distribution of shoulder disorders in secondary care is not reported. Most of the research in the shoulder field is done in hospital settings. If the majority of diagnoses are the same in general practice as in a specialist outpatient clinic, the generalisability of results from research done in specialist practices will tend to increase. The same might be true for diagnostic measures. Therefore, we considered it would be interesting to compare the diagnostic distribution in primary care with diagnoses given in a specialist practice.

The aim of this prospective study was to identify the diagnoses in a 1-year cohort in a hospital-based outpatient clinic using standardized diagnostic criteria and to compare the results with previous studies.

\section{Methods}

\section{Patient selection}

The data in this article were collected routinely from an outpatient clinic at the Department of Physical Medicine and Rehabilitation in Oslo University Hospital, Ullevål, Norway. Referrals to the clinic come mainly from primary care physicians.

All referrals regarding shoulder pain were marked with the World Health Organization International Classification of Diseases (ICD)-10 diagnosis m25.51 "Shoulder joint pain" in the hospital's administrative system (DoculivePasDoc 3.0, Siemens, Munich, Germany). All patients were examined by a medical doctor who took a history and performed a systematic clinical examination. When considered helpful, diagnostic ultrasound, X-rays, MRI, blood samples or neurophysiological investigations were conducted in addition before the final ICD-10 diagnosis was decided and recorded. The registration period started on 1 April 2008 and ended on 31 March 2009, giving a 1-year cohort.

The data were extracted from DoculivePasDoc through a report of all referrals marked $\mathrm{m} 25.51$. This report contained the patient's ID, date of visits, the final ICD-10 diagnosis given, as well as gender and duration of pain. The data were de-identified after review of the records. As the study was part of regular clinical activity and patient privacy was routinely taken into account, informed consent and permission from the Regional Ethics committee was not considered necessary.

\section{Clinical examination and diagnostic criteria}

Five medical doctors worked in the clinic during the registration period: four were specialists in physical medicine and rehabilitation and one was undergoing speciality training. Diagnostic criteria for the various diagnoses were established in accordance with the literature [8,10-17] as listed in Table 1 . The diagnostic criteria was based on an unsystematic literature search of PubMed and references cited in the captured articles.

The criteria were implemented prior to the data registration period. Training sessions in performing the clinical tests needed for diagnostic purposes were conducted to increase inter rater reliability which is reported to be varying from slight to substantial for the tests used, see Table 2. Some of the diagnoses were supported by supplementary imaging such as x-ray (osteoarthritis), MRI (where clinical examination were inconclusive), MRI arthrography (labral tears) or ultrasound (full thickness tears). However, most diagnoses were essentially based on the patient's medical history and a combination of clinical tests. The examiners followed the diagnostic scheme shown in Table 1 when diagnosing the patients. The diagnosis myalgia was chosen when specific diagnoses from the joints, rotator cuff or labrum were excluded, the patient felt pain over the muscles and the examiner triggered recognizable pain in the area by palpation. Reinforcement of the diagnostic routines was done regularly during the data collection period. Discussions concerning unclear cases were held in the clinic as well when needed. The tests used in the diagnostic procedures in Table 1 and their reliabilities are listed in Table 2.

\section{Statistical analysis}

The data were analysed using the statistical package SPSS v. 15.0 (SPSS Inc., Chicago, IL, USA). Descriptive statistics (mean, range and standard deviation, SD) were calculated. The relative proportion of one diagnosis (\% of all diagnoses) in an age group was calculated by dividing the number of patients with this diagnosis in that age group (nd-ag) with all patients in the same age group (n-ag) times 100; nd-ag/n-ag*100.

\section{Results}

During the 1-year registration period, 766 patients were referred to the clinic with a shoulder problem. Fifty-five per cent of the patients were women (419/766) and overall mean age in both sexes were 49 years (range 1593 ; SD \pm 14 ). The mean duration $( \pm \mathrm{SD}$ ) of shoulder pain was $29 \pm 42$ weeks for men and $26 \pm 38$ weeks in women. $471(61 \%)$ of the patients supplied a compact disc with a magnetic resonance imaging (MRI) scan or had a description of the scan attached to their referral letter. 
Table 1 Symptoms and diagnostic criteria for the most common shoulder diagnoses according to the ICD-10 code

\begin{tabular}{|c|c|c|c|c|c|}
\hline $\begin{array}{l}\text { ICD-10 diagnosis } \\
\text { with description }\end{array}$ & Symptoms & Diagnostic criteria & $\begin{array}{l}\text { Radiologic investigations } \\
\text { that might increase } \\
\text { diagnostic accuracy }\end{array}$ & $\begin{array}{l}\text { Number } \\
\text { (\% of all) in } \\
\text { this study }\end{array}$ & References \\
\hline M75.4 & \multirow{2}{*}{$\begin{array}{l}\text { Pain in the shoulder and } \\
\text { proximal lateral upper arm } \\
\text { exacerbated by activity }\end{array}$} & \multirow{2}{*}{$\begin{array}{l}\text { Typical pain and positive impingement } \\
\text { test and pain with isometric abduction } \\
\text { or external rotation }\end{array}$} & \multirow[t]{2}{*}{ None } & \multirow[t]{2}{*}{$275(36)$} & \multirow[t]{2}{*}{ [11-13] } \\
\hline $\begin{array}{l}\text { Subacromial pain } \\
\text { syndrome }\end{array}$ & & & & & \\
\hline M79.11 & \multirow{2}{*}{$\begin{array}{l}\text { Diffuse pain outside the } \\
\text { glenohumeral }(\mathrm{GH}) \text { joint } \\
\text { localised over muscles }\end{array}$} & \multirow{2}{*}{$\begin{array}{l}\text { Negative specific tests, pain when } \\
\text { palpating muscles }\end{array}$} & \multirow[t]{2}{*}{ None } & \multirow[t]{2}{*}{$132(17)$} & \multirow[t]{2}{*}{ [11] } \\
\hline $\begin{array}{l}\text { Myalgia in shoulder } \\
\text { muscles }\end{array}$ & & & & & \\
\hline M75.0 & \multirow{2}{*}{$\begin{array}{l}\text { Pain in the shoulder } \\
\text { exacerbated by activity. } \\
\text { Feeling of stiffness. }\end{array}$} & \multirow{2}{*}{$\begin{array}{l}\text { Reduced passive range of } \mathrm{GH} \\
\text { motion }>30^{\circ} \text { in two planes }\end{array}$} & \multirow[t]{2}{*}{ None } & \multirow[t]{2}{*}{$86(11)$} & \multirow[t]{2}{*}[14,15]{} \\
\hline Adhesive capsulitis & & & & & \\
\hline M75.1 & \multirow{2}{*}{$\begin{array}{l}\text { Pain in the shoulder. } \\
\text { Occasional feeling of } \\
\text { weakness }\end{array}$} & \multirow{2}{*}{$\begin{array}{l}\text { Positive impingement test and } \\
\text { weakness with isometric abduction } \\
\text { or external rotation }\end{array}$} & \multirow[t]{2}{*}{ MRI and US } & \multirow[t]{2}{*}{$58(8)$} & \multirow[t]{2}{*}[8,16]{} \\
\hline $\begin{array}{l}\text { Full thickness rotator } \\
\text { cuff tear }\end{array}$ & & & & & \\
\hline M19.8 & \multirow{2}{*}{$\begin{array}{l}\text { Pain on top of shoulder, } \\
\text { over the AC joint }\end{array}$} & \multirow{2}{*}{$\begin{array}{l}\text { Pain with joint palpation. } \\
\text { Osteoarthritis on X-ray, } \\
\text { US or MRI }\end{array}$} & \multirow[t]{2}{*}{ X-ray } & \multirow[t]{2}{*}{$31(4)$} & \multirow[t]{2}{*}[11,18]{} \\
\hline $\begin{array}{l}\text { Acromioclavicular (AC) } \\
\text { joint osteoarthritis }\end{array}$ & & & & & \\
\hline M19.0 & \multirow{2}{*}{$\begin{array}{l}\text { Pain in the shoulder. } \\
\text { Occasional feeling of } \\
\text { stiffness }\end{array}$} & \multirow[t]{2}{*}{ Osteoarthritis on X-ray or MRI } & \multirow[t]{2}{*}{ X-ray } & \multirow[t]{2}{*}{$29(4)$} & \multirow[t]{2}{*}[10,11]{} \\
\hline $\begin{array}{l}\text { Glenohumeral (GH) } \\
\text { joint osteoarthritis }\end{array}$ & & & & & \\
\hline M24.3 & \multirow{2}{*}{$\begin{array}{l}\text { Pain in the shoulder } \\
\text { and/or feeling of } \\
\text { instability }\end{array}$} & \multirow{2}{*}{$\begin{array}{l}\text { Positive apprehension/relocation } \\
\text { test. Labral tear on MRA }\end{array}$} & \multirow[t]{2}{*}{ MRA } & \multirow[t]{2}{*}{$24(3)$} & \multirow[t]{2}{*}{ [11] } \\
\hline $\begin{array}{l}\text { Anterior labral tear } \\
\text { or instability }\end{array}$ & & & & & \\
\hline M24.3 & \multirow{2}{*}{$\begin{array}{l}\text { Pain in the shoulder. } \\
\text { Occasional feeling of } \\
\text { instability }\end{array}$} & \multirow{2}{*}{$\begin{array}{l}\text { Positive O'Brian test and SLAP } \\
\text { lesion on MRA }\end{array}$} & MRA & $16(3)$ & [11] \\
\hline SLAP lesion & & & & & \\
\hline M25.2 & Pain in and around the & Positive sulcus sign and passive & None & $9(2)$ & {$[11]$} \\
\hline $\begin{array}{l}\text { Multidirectional } \\
\text { instability }\end{array}$ & $\begin{array}{l}\text { shoulder. Occasıonal } \\
\text { feeling of instability }\end{array}$ & & & & \\
\hline
\end{tabular}

Main symptoms, diagnostic criteria and radiological investigations that might have increased the accuracy of the diagnostic criteria are listed with and references for the used criteria.

Key: MRI, magnetic resonance imaging; MRA, MRI arthrography; SLAP, superior labrum anterior to posterior; US, ultrasound.

The numbers (\%) of patients diagnosed with different diagnoses are shown.

The most common diagnoses were subacromial pain syndrome (36\%), followed by myalgia (17\%), adhesive capsulitis (11\%), full thickness rotator cuff tears (8\%), acromioclavicular (AC) joint osteoarthritis (4\%) and glenohumeral $(\mathrm{GH})$ joint osteoarthritis $(4 \%)$. The relative proportions of these diagnoses are shown in Figure 1.

Subacromial pain was most frequent in patients aged between 40 and 60 years. For men, this diagnosis increased with age, but in women it was reduced after age 70. For myalgia, most affected individuals were also aged 40-60. The relative proportion of this diagnosis was highest in the lowest age group, $44 \%$ in women and $29 \%$ in men, decreasing almost linearly with age to less than $5 \%$ in both women and men aged over 70 . Adhesive capsulitis was most frequent between 40 and 70 years of age for both men and women, as was the case for the proportion of this diagnosis. For full-thickness rotator cuff tears and glenohumeral osteoarthritis, almost all affected individuals were aged over 50 years. The proportion of both full-thickness rotator cuff tears and glenohumeral osteoarthritis increased dramatically from less than $5 \%$ before 50 years, up to $30 \%$ of all patients over 70 except for men with osteoarthritis (17\%). Acromioclavicular osteoarthritis was most frequent for patients aged 40-70.

The remaining diagnoses were grouped into labral tears $(6 \%)$, neurological conditions $(4 \%)$, other shoulder diagnoses (5\%) and non-shoulder diagnoses (1\%). Of the study cohort, 26 patients (3\%) did not get a specific diagnosis and were labelled "shoulder pain NUD". Of the 49 patients with labral tears, 19 had anterior tears and five had posterior tears. Sixteen had superior labrum anterior to posterior (SLAP) lesions and nine were diagnosed with multidirectional instability. There were 31 patients with neurological conditions. Of these, 17 had cervicobrachialgia without radiculopathy, five had radiculopathy and nine suffered from mononeuritis in the shoulder girdle. Among other shoulder diagnoses, we found 10 sequelae after fracture, seven with AC-joint rupture and 


\begin{tabular}{|c|c|c|}
\hline Test & $\begin{array}{l}\text { Inter rater reliability. ICC or } \\
\text { Kohens kappa (K). }(95 \% \mathrm{CI}) \\
\text { or mean. }\end{array}$ & Reference \\
\hline \multicolumn{3}{|l|}{$\begin{array}{l}\text { Passive glenohumeral range } \\
\text { of motion }\end{array}$} \\
\hline - External rotation & $0.88-0.90,0.87-0.93$ & {$[19,20]$} \\
\hline - Abduction & $0.84-0.87,0.85-0.98$ & {$[19,21]$} \\
\hline \multicolumn{3}{|l|}{ Isometric muscle tests } \\
\hline - Abduction (empty can) & $0.30-0.94(K)$ & {$[22]$} \\
\hline - External rotation & $0.37-0.90(K)$ & {$[23]$} \\
\hline - Belly press & $0.61(K)$ & {$[24]$} \\
\hline \multicolumn{3}{|l|}{ Special tests } \\
\hline Hawkins impingement test & 0.18-0.91 (K), $0.38(K)$ & {$[22,24]$} \\
\hline AC joint palpation & na, high specificity (0.73) & {$[17,24]$} \\
\hline Apprehension test & $0.31-0.47$ & {$[22]$} \\
\hline Relocation test & $0.31-0.71$ & {$[22]$} \\
\hline O’Brien test & $0.24-0.38(K)$ & {$[24]$} \\
\hline Sulcus sign & 0.60 & [22] \\
\hline
\end{tabular}

seven with biceps tendinopathy only. There were one to three patients with the following diagnoses: sternoclavicular joint pathology, avascular necrosis of the caput humeri, snapping scapulae, postoperative pain, neuropathic pain, septic bursitis and generalised hypermobility syndrome. The eight non-shoulder diagnoses included pulmonary tumour, polymyalgia rheumatica, thoracic back pain, psoriatic cervical osteochondritis, myopathy and monoarthritis in the elbow. The relative proportions of the less frequent diagnoses labral tears, neurological conditions, other shoulder diagnoses and non-shoulder diagnoses are shown in Figure 2 on a different scale than the common diagnoses shown in Figure 1.

\section{Discussion}

\section{Main findings}

Subacromial pain syndrome was the most common shoulder diagnosis (36\%) and it increased with age for both men and women. Then myalgia in the shoulder girdle (17\%) and adhesive capsulitis (11\%) followed. Myalgia was the most frequent diagnosis in persons under 40 years for both genders, decreasing linearly with age. Adhesive capsulitis was found almost entirely in patients aged 40-70 with an even sex distribution except for a peak in women between 50 and 59 years. The degenerative diseases full thickness rotator cuff tear (8\%) and glenohumeral osteoarthritis (4\%) represented fewer patients, but accounted together for almost $60 \%$ of the patients over 70 years of age. In men between 50 and 69 years, glenohumeral osteoarthritis was six times more frequent than in women, among whom the diagnosis was present almost entirely after the age of 70 years.

\section{Methodological aspects}

The results in this study were collected from routine diagnostic practice in an outpatient clinic. The practice was based on a literature-based written diagnostic consensus reinforced by regular supervision, meetings on a regular basis and discussions regarding difficult cases. The diagnostic criteria listed in Table 1 are mainly based on symptoms and clinical investigations and only supported by imaging in three of our nine diagnostic categories. However, most of the patients either brought (471 (61\%)) or had imaging, mostly with MRI, but also with X-rays and diagnostic ultrasound. This supplementary use of imaging might be a problem in this study, as imaging give many incidental findings not necessarily contributing to the symptoms. However, this study lacked the rigid framework of a scientific study with a systematic pre-approved registration. There was no quality assessment of potential differences between the involved consultants. Intra- and inter rater reliability measures on the performance of the clinical tests were not obtained, although training before the registration period was done. The lack of inter rater reliability testing is an important limitation of this study and might lead to variability in prevalences of the selected diagnoses.

For 17 patients, the pre-set diagnosis was not changed to a more specific diagnosis after the consultation due to lacking registration from the consultants. To include these patients the senior consultant (NGJ) corrected these diagnoses by going through these medical records after the registration period, and retrospectively set a diagnosis according to the methods used in this study.

The most common diagnoses of shoulder ailments are based on sets of criteria in the absence of tissue specific characteristics. There is no conclusive gold standard and the pain generator is not known for conditions such as subacromial pain syndrome and myalgia. This is even true in the degenerative diseases where studies have shown both full thickness rotator cuff tears [8] and osteoarthritis [9] in non-painful shoulders. Therefore, the diagnostic criteria sets used in the literature might differ and cause frequency differences across studies. Our choice of criteria sets was mostly based on the Southampton examination schedule $[11,25]$, and additional research-based criteria were added when considered adequate (Table 1). The myalgia diagnosis is disputed and argued to be a symptom and not a specific diagnosis. In this study myalgia is a symptom diagnosis supplemented with positive findings by muscle palpation. 


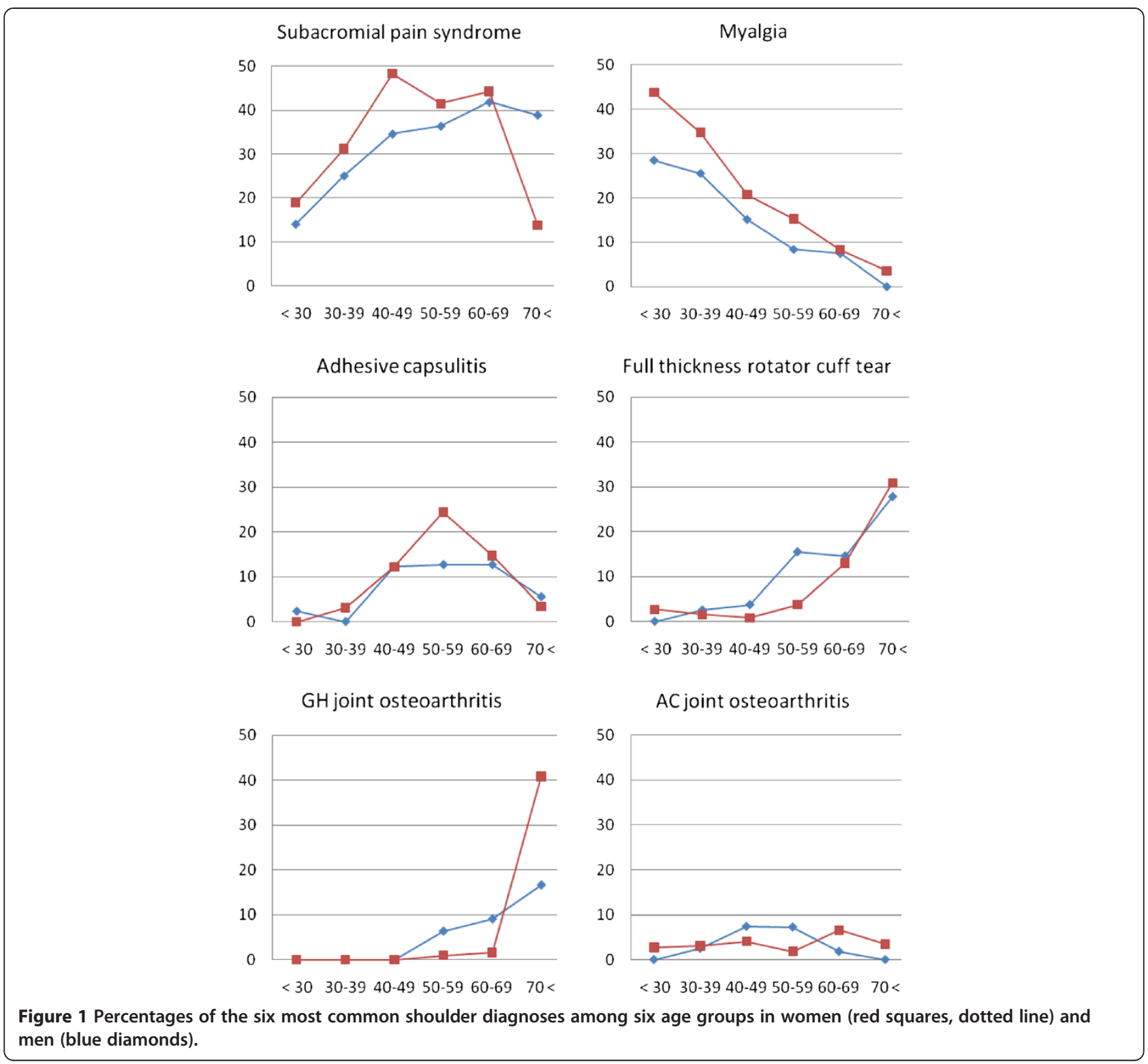

We report only one main diagnosis per person although some patients had more than one diagnosis. This have probably affected the results, particularly in the myalgia and AC joint osteoarthritis groups. AC joint osteoarthritis is reported as increasingly present with age in persons without shoulder pain [9] and was most likely underestimated in older age groups in our study. Myalgia is almost always present in joint diseases as an additional extra-articular source of pain but was only accounted for when present as the main diagnosis in our cohort. Probably myalgia and AC joint osteoarthritis would have been among the most prevalent secondary and tertiary diagnoses, but due to the lack of registration of more than one main diagnosis this study can not present results on the distribution of secondary and tertiary diagnosis.

\section{Discussion of our results compared with other reports}

A search of the literature did not reveal any studies reporting the prevalence of shoulder diagnoses in secondary care. Three studies reporting shoulder diagnoses from population studies or primary care were identified. Walker-Bone et al. [4] (447 shoulders) recruited patients from a questionnaire study of 9696 persons in the general population and 365 shoulder diagnoses were made. Östör et al. [5] investigated a 1-year cohort from two general practices (131 shoulders). These two studies were from England, whereas van der Windt et al. [6] 

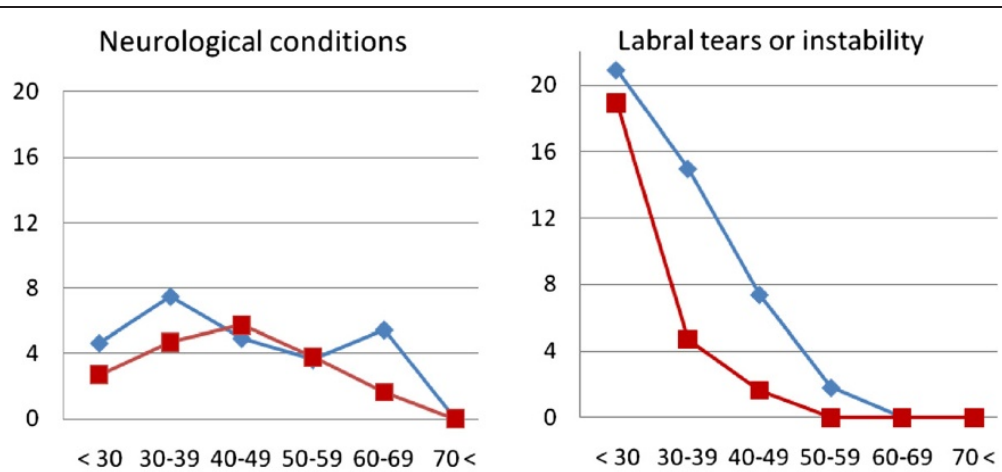

Other shoulder diagnoses

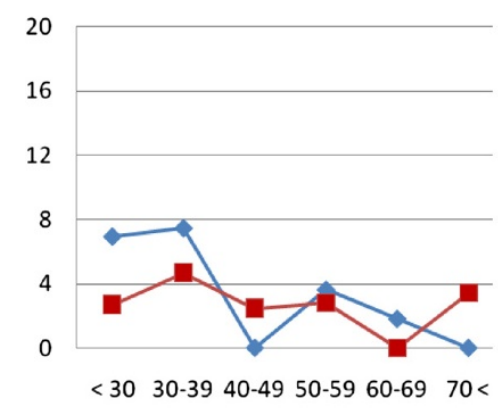

Shoulder pain NUD

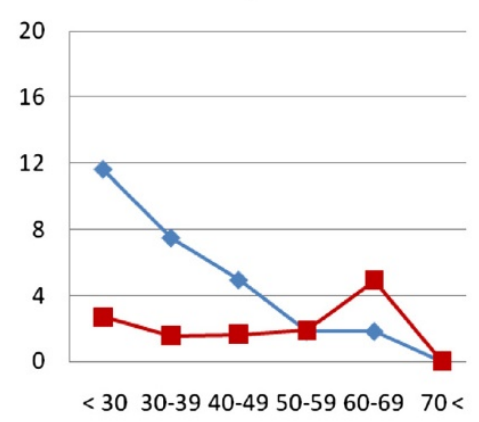

Non shoulder diagnoses

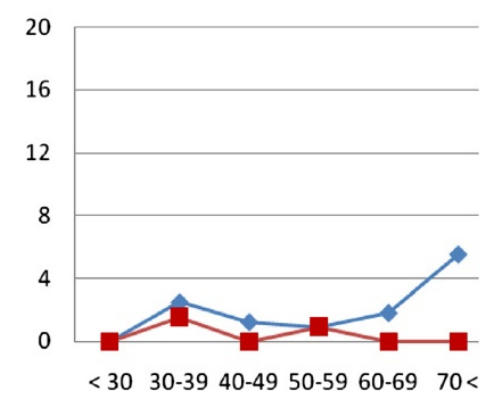

Figure 2 Percentages of less frequent shoulder diagnoses and non-shoulder diagnoses among six age groups in women (red squares, dotted line) and men (blue diamonds). The $\mathrm{Y}$-axis covers $0-20 \%$ of all cases by age group.

described a Dutch 1-year cohort (392 shoulders) recruited from 11 general practitioners.

The percentages of the six most common diagnoses in these three population studies are shown in Table 3 together with percentages from our study.

Walker-Bone et al. reported from a population-based study in which the participants complained of shoulder pain in the previous week when asked, but did not seek help themselves. This population probably had fewer complaints regarding both duration and pain intensity compared to the other two studies that are based on patients seeking help for their shoulder symptoms. It is surprising that Walker-Bone et al. found adhesive capsulitis in 55\% of the cases because this is a disease regarded to cause a lot of pain and restriction in function. In contrast the other two studies found $15 \%$ and $21 \%$ of this diagnosis.
Table 3 Percentages of the most common diagnoses in four studies

\begin{tabular}{lllll}
\hline & $\begin{array}{l}\text { This } \\
\text { study }\end{array}$ & Walker-Bone [4] & Östör [5] & $\begin{array}{l}\text { Van der } \\
\text { Windt [6] }\end{array}$ \\
\hline $\begin{array}{l}\text { Subacromial pain } \\
\text { syndrome }\end{array}$ & 36 & $30^{\mathrm{a}}$ & $86^{\mathrm{b}}$ & $4^{\mathrm{c}}$ \\
$\begin{array}{l}\text { Adhesive capsulitis } \\
\text { Myalgia }\end{array}$ & 11 & 55 & 15 & 21 \\
$\begin{array}{l}\text { Full thickness rotator } \\
\text { cuff tear }\end{array}$ & 8 & - & 6 & - \\
$\begin{array}{l}\text { Acromioclavicular } \\
\text { Osteoarthritis }\end{array}$ & 4 & 6 & - & - \\
$\begin{array}{l}\text { Glenohumeral } \\
\text { osteoarthritis }\end{array}$ & 4 & - & 31 & 5 \\
\hline
\end{tabular}

ancludes rotator cuff tendonitis and subacromial bursitis.

${ }^{b}$ Includes impingement and rotator cuff tendinopathy.

Includes tendonitis and chronic bursitis. 
The subacromial pain syndrome diagnosis was separated into subdiagnoses in the other studies as impingement and rotator cuff tendinopathy [5], rotator cuff tendinitis and subacromial bursitis [4] or as tendonitis and chronic bursitis [6], giving the opportunity of multiple diagnoses in the same person. This might have affected the reported numbers of patients with subacromial pain syndrome. Separation of specific diagnoses in the subacromial area is disputed, both on the grounds of clinical tests and of radiological investigations [26,27]. Therefore, in our study, we chose to collect all patients with subacromial pain and no other specific tissue diagnosis as listed above into one group called subacromial pain syndrome. Östör et al. reported subacromial pain in $86 \%$ of their subjects, double the rate of the other studies. Their criteria included discomfort with isometric testing of any of the rotator cuff muscles. Isometric testing gives a co contraction of all cuff muscles and this will increase the compressive forces in the $\mathrm{GH}$ joint, engage the trapezius and scapular muscles and may trigger pain from capsulitis in the $\mathrm{GH}$ joint or from painful muscles [14]. Isometric tests with the arm elevated produce shear forces in the AC joint [28]. Pain during isometric testing might have led to overdiagnosing subacromial pain.

Surprisingly, none of the other studies reported full thickness rotator cuff tears or glenohumeral osteoarthritis. In our study, $14 \%$ of all diagnoses in the 60-69 age group were tears, rising to $30 \%$ in persons over 70 years of age. Glenohumeral osteoarthritis was the most frequent diagnosis in women aged over 70 years (41\%) and accounted for $17 \%$ of the diagnoses in men of this age group. This large difference in results between the four studies might occur because these degenerative diagnoses are rare in primary care. On the other hand, one would expect scattered cases in a 1-year cohort with ages up to 87 years. In our cohort, all diagnoses of glenohumeral osteoarthritis and full thickness rotator cuff tears were supported by MRI scans, which have very high sensitivity for these diagnoses [29]. This might account for a higher proportion of these diagnoses in our group. On the other hand full thickness cuff tears is frequently found also in non-painful shoulders in the elderly [30] and may have led to overdiagnosing these conditions in our population. However, there were only 28 patients with osteoarthritis and full thickness tears in our cohort of 766 . The other cohorts in the literature were smaller than ours and a random distribution of diagnoses may also explain some of the variation in the results.

In the present study, AC joint osteoarthritis had to fulfil the clinical criteria in Table 1 and to be the main diagnosis to be registered. In clinical practice, symptomatic AC-joint osteoarthritis often coexists with, or is a part of, a subacromial pain syndrome. Therefore, the number of AC-joint osteoarthritis diagnoses in our study might have been underestimated because subacromial pain was chosen most often as the main diagnosis. Östör et al. found a high percentage of AC joint osteoarthritis compared with the other studies. This might be because their diagnostic criteria included either tenderness in the $\mathrm{AC}$ joint region or pain on adduction of the arm only. Adduction is often painful in patients with subacromial pain syndrome and always in cases of adhesive capsulitis and this may have led to an overestimation of $\mathrm{AC}$ joint osteoarthritis in their study.

Walker-Bone et al. did not find any age or genderrelated difference in diagnoses, and the other reports did not detail such differences. In our study, the most striking difference was the approximately $10 \%$ higher proportion of myalgia in women aged up to 60 years, a higher proportion of subacromial pain syndrome in women under 50 years of age and a higher proportion of full thickness tears after the age of 60 for both sexes.

In terms of the duration of pain, there were only one comparable study from primary care [6]. Östör et al. reported the median duration of pain to be 10 weeks. The participants in our cohort had suffered from shoulder pain for 26 weeks on average at the consultation. This might imply a more chronic group in secondary care, which is also to be expected. The rather large difference in the frequencies of the diagnose myalgia might be explained by the different diagnostic criteria used in the studies but it could also partly reflect the longer duration of pain in secondary care.

The generalisability of this study is limited because of differences in the spectre of diagnoses used compared to other studies, and also the methodological limitations with the lack of inter rater reliability testing, the missing secondary and tertiary diagnoses and the pragmatic use of clinical tests and imaging as diagnostic tools.

However, our data is the first description of the shoulder diagnoses in a secondary care setting, and we found that the most frequent diagnoses were subacromial pain, myalgia and adhesive capsulitis. Our results from secondary care are partly in line with studies from primary care settings. In all these studies subacromial pain and adhesive capsulitis represented $50 \%$ or more of the cases for both men and women. Consequently, these two diagnoses should always be considered in patients presenting with shoulder pain in all levels of health care.

\section{Conclusions}

This is the first report on the prevalence and age and gender related prevalence of specific shoulder diagnoses in secondary care. The most frequent diagnoses set in our clinic were subacromial pain syndrome, myalgia in the shoulder girdle and adhesive capsulitis. Subacromial pain syndrome and adhesive capsulitis were most frequent in 
the middle age and the degenerative diseases were almost only present after the age of 60 and represented $60 \%$ of all diagnoses in persons over 70 . In people under 40 myalgia and instabilities were most frequent.

\section{Competing interests}

The authors declare that they have no competing interests.

\section{Authors' contributions}

NGJ planned and designed the study, took part in all phases of the study and are responsible for the work as a whole. BN contributed in analysis and interpretation of data, drafting and revising the manuscript and approved the final submitted version. Both authors read and approved the final manuscript.

\section{Authors' information}

NGJ is head of the outpatient clinic for musculoskeletal diseases and responsible for the quality of diagnostic procedures in his department and also for specialist education in the field in Norway. BN is professor in general practice and do research on the epidemiology of musculoskeletal pain.

\section{Acknowledgements}

The authors would like to thank the medical doctors in the Department of Physical Medicine and Rehabilitation, Oslo University Hospital, Oslo, Norway, for their contribution in collecting the data.

\section{Author details}

'Department of Physical Medicine and Rehabilitation, Oslo University Hospital, Ullevål, Postboks 4956 Nydalen, 0424 Oslo, Norway. ${ }^{2}$ Department of General Practice, Institute of Health and Society, University of Oslo, Oslo, Norway.

Received: 4 September 2013 Accepted: 13 March 2014

Published: 18 March 2014

\section{References}

1. Natvig B, Picavet HS: The epidemiology of soft tissue rheumatism. Best Pract Res Clin Rheumatol 2002, 16:777-793.

2. Pope DP, Croft PR, Pritchard CM, Silman AJ: Prevalence of shoulder pain in the community: the influence of case definition. Ann Rheum Dis 1997, 56:308-312.

3. Luime JJ, Koes BW, Hendriksen IJ, Burdorf A, Verhagen AP, Miedema HS, Verhaar JA: Prevalence and incidence of shoulder pain in the general population; a systematic review. Scand J Rheumatol 2004, 33:73-81.

4. Walker-Bone K, Palmer KT, Reading I, Coggon D, Cooper C: Prevalence and impact of musculoskeletal disorders of the upper limb in the general population. Arthritis Rheum 2004, 51:642-651.

5. Ostor AJ, Richards CA, Prevost AT, Speed CA, Hazleman BL: Diagnosis and relation to general health of shoulder disorders presenting to primary care. Rheumatology (Oxford) 2005, 44:800-805.

6. van der Windt DA, Koes BW, de Jong BA, Bouter LM: Shoulder disorders in general practice: incidence, patient characteristics, and management. Ann Rheum Dis 1995, 54:959-964.

7. Ostor AJ, Richards CA, Tytherleigh-Strong G, Bearcroft PW, Prevost AT, Speed CA, Hazleman BL: Validation of clinical examination versus magnetic resonance imaging and arthroscopy for the detection of rotator cuff lesions. Clin Rheumatol 2013, 32:1283-1291.

8. Moosmayer S, Smith HJ, Tariq R, Larmo A: Prevalence and characteristics of asymptomatic tears of the rotator cuff: an ultrasonographic and clinical study. J Bone Joint Surg Br 2009, 91:196-200.

9. Shubin Stein BE, Ahmad CS, Pfaff CH, Bigliani LU, Levine WN: A comparison of magnetic resonance imaging findings of the acromioclavicular joint in symptomatic versus asymptomatic patients. J Shoulder Elbow Surg 2006, 15:56-59.

10. Brox Jl, Lereim P, Merckoll E, Finnanger AM: Radiographic classification of glenohumeral arthrosis. Acta Orthop Scand 2003, 74:186-189.

11. Palmer K, Walker-Bone K, Linaker C, Reading I, Kellingray S, Coggon D, Cooper $C$ : The Southampton examination schedule for the diagnosis of musculoskeletal disorders of the upper limb. Ann Rheum Dis 2000, 59:5-11.
12. Brox Jl, Gjengedal E, Uppheim G, Bohmer AS, Brevik JI, Ljunggren AE, Staff $\mathrm{PH}$ : Arthroscopic surgery versus supervised exercises in patients with rotator cuff disease (stage II impingement syndrome): a prospective, randomized, controlled study in 125 patients with a $21 / 2$-year follow-up. J Shoulder Elbow Surg 1999, 8:102-111.

13. Ekeberg OM, Bautz-Holter E, Tveita EK, Juel NG, Kvalheim S, Brox Jl: Subacromial ultrasound guided or systemic steroid injection for rotator cuff disease: randomised double blind study. BMJ 2009, 338:a3112.

14. Treita EK, Tariq R, Sesseng S, Juel NG, Bautz-Holter E: Hydrodilatation, corticosteroids and adhesive capsulitis: a randomized controlled trial. BMC Musculoskelet Disord 2008, 9:53.

15. Hand GC, Athanasou NA, Matthews T, Carr AJ: The pathology of frozen shoulder. J Bone Joint Surg Br 2007, 89:928-932.

16. Murrell GA, Walton JR: Diagnosis of rotator cuff tears. Lancet 2001, 357:769-770.

17. Walton J, Mahajan S, Paxinos A, Marshall J, Bryant C, Shnier R, Quinn R, Murrell GA: Diagnostic values of tests for acromioclavicular joint pain. $J$ Bone Joint Surg Am 2004, 86-A:807-812.

18. Favre P, Senteler M, Hipp J, Scherrer S, Gerber C, Snedeker JG: An integrated model of active glenohumeral stability. J Biomech 2012, 45:2248-2255.

19. Riddle DL, Rothstein JM, Lamb RL: Goniometric reliability in a clinical setting. Shoulder measurements. Phys Ther 1987, 67:668-673.

20. Lewis JS, Valentine RE: Intraobserver reliability of angular and linear measurements of scapular position in subjects with and without symptoms. Arch Phys Med Rehabil 2008, 89:1795-1802.

21. Valentine RE, Lewis JS: Intraobserver reliability of 4 physiologic movements of the shoulder in subjects with and without symptoms. Arch Phys Med Rehabil 2006, 87:1242-1249.

22. May S, Chance-Larsen K, Littlewood C, Lomas D, Saad M: Reliability of physical examination tests used in the assessment of patients with shoulder problems: a systematic review. Physiotherapy 2010, 96:179-190.

23. Baums MH, Spahn G, Nozaki M, Steckel H, Schultz W, Klinger HM: Functional outcome and general health status in patients after arthroscopic release in adhesive capsulitis. [Erratum appears in Knee Surg Sports Traumatol Arthrosc. 2007 May;15(5):687]. Knee Surg Sports Traumatol Arthrosc 2007, 15:638-644.

24. Cadogan A, Laslett M, Hing W, McNair P, Williams M: Interexaminer reliability of orthopaedic special tests used in the assessment of shoulder pain. Man Ther 2011, 16:131-135.

25. Walker-Bone K, Byng P, Linaker C, Reading I, Coggon D, Palmer KT, Cooper C: Reliability of the Southampton examination schedule for the diagnosis of upper limb disorders in the general population. Ann Rheum Dis 2002, 61:1103-1106

26. Alqunaee M, Galvin R, Fahey T: Diagnostic accuracy of clinical tests for subacromial impingement syndrome: a systematic review and meta-analysis. Arch Phys Med Rehabil 2012, 93:229-236.

27. Harrison AK, Flatow EL: Subacromial impingement syndrome. J Am Acad Orthop Surg 2011, 19:701-708.

28. O'Brien SJ, Pagnani MJ, Fealy S, McGlynn SR, Wilson JB: The active compression test: a new and effective test for diagnosing labral tears and acromioclavicular joint abnormality. Am J Sports Med 1998, 26:610-613.

29. de Jesus JO, Parker L, Frangos AJ, Nazarian LN: Accuracy of MRI, MR arthrography, and ultrasound in the diagnosis of rotator cuff tears: a meta-analysis. AJR Am J Roentgenol 2009, 192:1701-1707.

30. Moosmayer S, Tariq R, Stiris MG, Smith HJ: MRI of symptomatic and asymptomatic full-thickness rotator cuff tears. A comparison of findings in 100 subjects. Acta Orthop 2010, 81:361-366.

doi:10.1186/1471-2474-15-89

Cite this article as: Juel and Natvig: Shoulder diagnoses in secondary care, a one year cohort. BMC Musculoskeletal Disorders 2014 15:89. 